NASA FACULTY FELLOWSHIP PROGRAM

\author{
MARSHALL SPACE FLIGHT CENTER \\ THE UNIVERSITY OF ALABAMA
}

\title{
IMPEDANCE-BASED STRUCTURAL HEALTH MONITORING FOR COMPOSITE LAMINATES AT CRYOGENIC ENVIRONMENTS
}

\author{
Prepared By: \\ Kevin Tseng \\ Academic Rank: \\ Assistant Professor \\ Institution and Department: \\ Vanderbilt University \\ Department of Civil \& \\ Environmental Engineering \\ NASA/MSFC Directorate: \\ Engineering \\ MSFC Colleague: \\ Dr. Mike Tinker
}




\section{$\underline{\text { Introduction }}$}

One of the important ways of increasing the payload in a reusable launch vehicle (RLV) is to replace heavy metallic materials by lightweight composite laminates. Engineers and scientists have studied many metallic materials thoroughly, due to the long history of practical usage in many aerospace and aeronautical structures. Compared to metallic materials, composite laminates are a relatively new class of materials and therefore require more attention to ensure the safety and reliability when they are used.

Among various parts and systems of the RLV, this project focuses on tanks containing cryogenic fuel. Historically, aluminum alloys have been used as the materials to construct fuel tanks for launch vehicles. To replace aluminum alloys with composite laminates or honeycomb materials, engineers have to make sure that the composites are free of defects before, during, and after launch. In addition to robust design and manufacturing procedures, the performance of the composite structures needs to be monitored constantly.

In recent years, the impedance-based health monitoring technique has shown its promise in many applications. This technique makes use of the special properties of smart piezoelectric materials to identify the change of material properties due to the nucleation and progression of damage. The piezoceramic patch serves as a sensor and an actuator simultaneously. The electromechanical impedance approach using smart piezoelectric ceramic transducers having selfactuating and sensing capabilities has shown potential applications in damage detection in structural systems. Sun et al. [4] and later Ayres et al. [1] reported the use of piezoelectric ceramic patches (PZT) for damage detection and characterization on a laboratory- size truss structure and a prototype truss joint, respectively. The damage detection method is based on the principle of electro-mechanical coupling between the host structure and the bonded PZT patch. The structural impedance modifies the effective electrical impedance of the PZT, and the corresponding change in the driving point impedance is used to identify incipient damage in the structure Giurgiutiu et al. [3]. See Chang [2] for more references.

The piezoelectric patch is bonded onto an existing structure or embedded into a new structure and electrically excited at high frequencies. The signature (impedance or admittance) is extracted as a function of the exciting frequency and is compared with the baseline signature of the healthy state. The damage is quantified using root mean square deviation (RMSD) in the impedance signatures with respect to the baseline signature. A major advantage of this technique is that the procedure is nondestructive in nature and does not perturb the properties and performance of the materials and structures.

This project aims at applying the impedance-based nondestructive testing technique to the damage identification of composite laminates at cryogenic temperature. These materials have potential application for fuel tanks in future RLV's. Regular piezoceramic sensor/actuators are tested to assess their performance under cryogenic temperature. Composite laminates with attached piezoceramic patches are submerged into liquid nitrogen and the impedance signatures are taken. The results show that regular piezoceramic materials are likely not suitable for cryogenic applications. A significant amount of noise can be observed in the impedance signature when the piezoceramic patch is submerged at liquid nitrogen. However, these findings 
do not suggest that conventional piezoceramic devices cannot be used for non-cryotank RLV or other applications.

To remedy the deficiency in performance for cryogenic applications, a novel single crystal piezeceramic material, specially designed to function at cryogenic environment, has been identified. This new piezoceramic material appears to be a promising candidate for impedancebased nondestructive testing for composite laminates at cryogenic temperature. More comprehensive tests are planned to assess the performance of the single crystal piezoceramic materials at cryogenic temperature.

\section{Composite Laminates}

The composite panels tested in this project are 6-ply woven carbon fiber laminates. Figure 1 is the image of the side of a composite panel under microscope. Woven laminates is selected for the test because their flexibility in forming curved surfaces. Curved surfaces are needed in the construction of fuel tanks for RLV's.

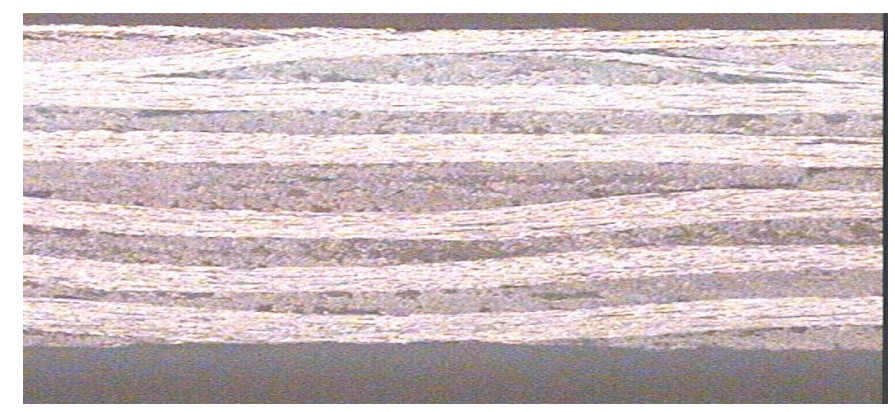

Figure 1: Composite Laminate Ply Count

\section{$\underline{\text { Impact Damage }}$}

Damage in the composite panel is introduced by the impact facility as shown in Figure 2. Various level of damage can be created at the center of the test article by controlling the weight and drop-height of the impact head. The second picture in Figure 2 shows two different levels of impact damage to the composite panel.
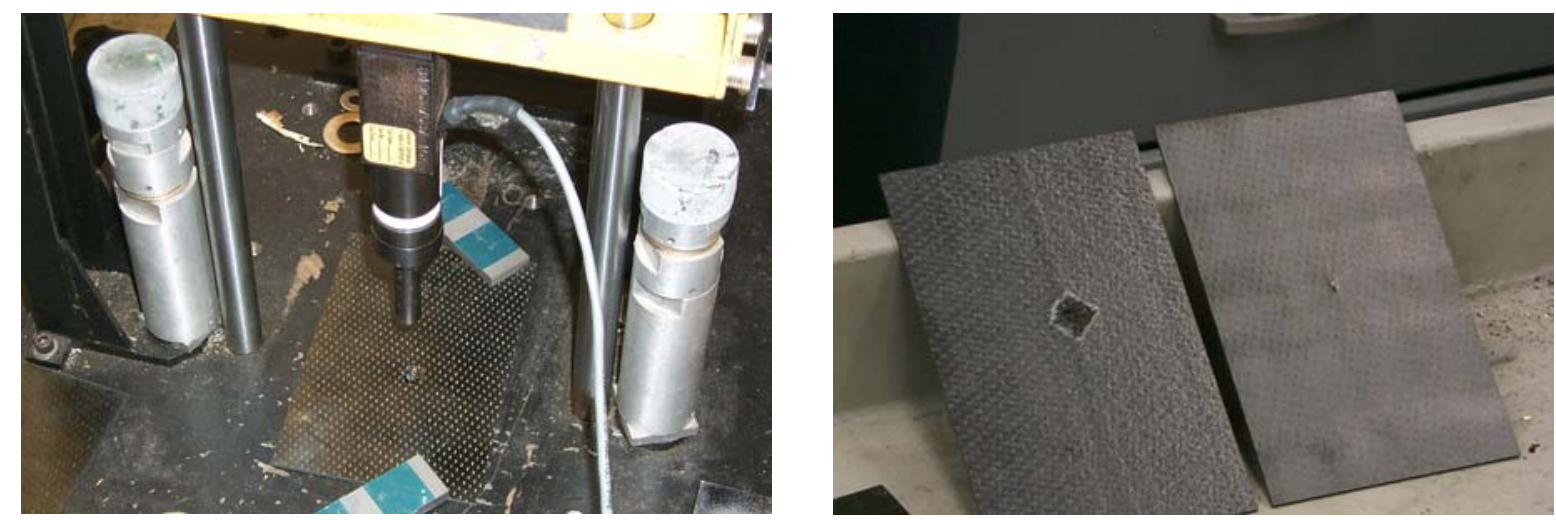

Figure 2: Impact Damage at the Center of the Composite Panel 


\section{Cryogenic Environment}

To assess the performance of the piezoceramic patch, the test article is placed in a pan and submerged in liquid nitrogen. Liquid nitrogen has a constant temperature of $-318^{\circ} \mathrm{F}$. The impedance signatures are taken while the test article is under cryobath.

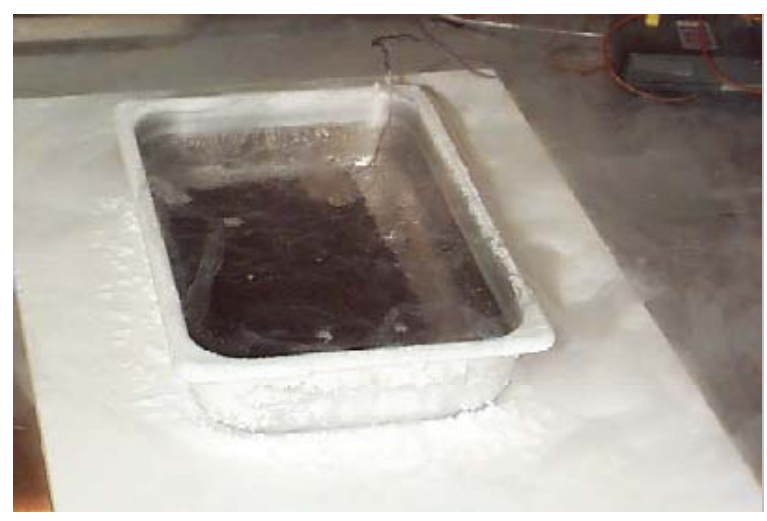

Figure 3: Test Article Submerged in Liquid Nitrogen

\section{Combined Cryogenic and Impact Damage Tests}

In order to evaluate the performance of piezoceramic patches for damage identification at cryogenic temperature, a series of tests combining both impact damage and cryogenic thermal load are conducted. All test articles are configured with regular piezoceramic patches attached.

\section{$\underline{\text { Results }}$}

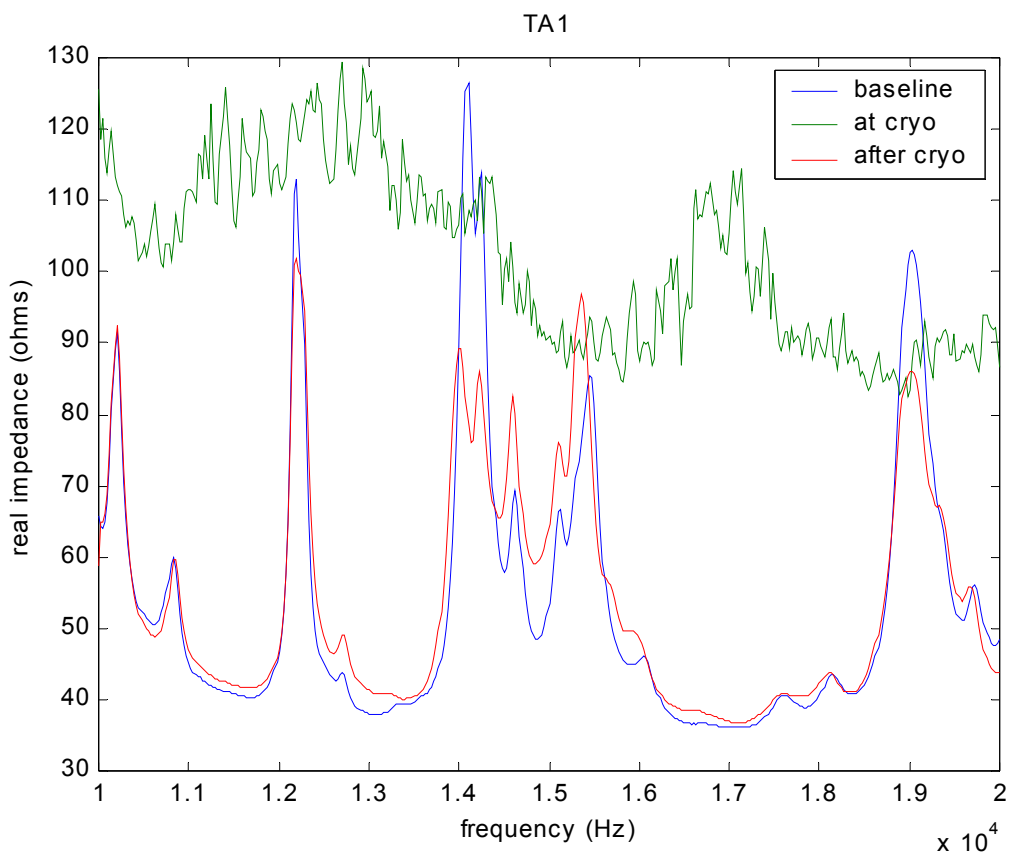

Figure 4: Impedance Signatures Before, During, and After Cryobath 
Figure 4 shows a typical impedance signature for the tests conducted in this project. The regular piezoceramic patch functions well before the test article is submerged into liquid nitrogen. During the cryobath, the piezoceramic patch is at the cryogenic temperature of liquid nitrogen. A significant amount of noise can always be observed in the impedance signature for all the test articles. The results also show that after the test articles are removed from the cryobath and returned to room temperature, the performance of piezeoceramic patches seems to recover.

\section{Single-Crystal Piezoceramic Patch}

Recently, a single-crystal piezoceramic material has been designed and manufactured by TRS Ceramics Inc. to be used for cryogenic environments. This special piezoceramic material can generate much more energy at cryogenic temperature as compared to the regular piezoceramic materials. More tests with single-crystal piezoceramic patches are planned to verify their performance at the cryogenic temperature of liquid nitrogen.

\section{Conclusions}

The test results show that regular piezoceramic patches are not suitable for impedance-based nondestructive damage identification at cryogenic temperature. A significant amount of noise can be observed in the impedance signature when regular piezoceramic patches are submerged into liquid nitrogen. A single-crystal piezoceramic material, specially created for cryogenic applications, has been identified. More tests have been planned to assess the performance of the single-crystal piezoceramic material for damage identification at cryogenic environments.

\section{Acknowledgements}

The author would like to thank the entire team of engineers in the Structural Dynamics and Loads Group of the Marshall Space Flight Center's Engineering Directorate. Special thanks go to the author's colleague, Mike Tinker, who has provided the author all the support during the summer. The author is also grateful to John Lassiter, Dan Peairs, Andy Hodge, Erin Richardson, Stephen Herald, Freida Lowery, and John Lowery for their assistance.

\section{$\underline{\text { References }}$}

[1] Ayers J. W., Lalande F., Chaudhry Z., and Rogers C. A. (1998), Qualitative impedancebased health monitoring of civil infrastructures, Smat Mater. Struct., vol. 7, pp. 599-605.

[2] Chang, F. K., editor (2001), Proceeding of the $3^{\text {rd }}$ International Workshop on Structural Health Monitoring, Stanford, California, 2001.

[3] Giurgiutiu V., Reynolds A., and Rogers C. A. (1999), Experimental investigation of E/M impedance health monitoring for spot-welded structural joints, J. Intell. Mater. Syst. Struct., vol. 10 , pp. 802-812.

[4] Sun, F.P., Chaudhry, Z., Rogers, C.A., Majmundar, M., and Liang, C. (1995), Automated Real-Time Structure Health Monitoring Via Signature Pattern Recognition, Proceedings of Smart Structures and Materials Conference, San Diego, California, SPIE, vol. 2443, pp. 236-247. 